\begin{tabular}{lllllllllllllllllllllllllllllllll}
\hline$R$ & $E$ & $V$ & I & S & T & A & D & E & E & S & T & U & D & I & O & S & I & N & T & E & $R$ & R & N & A & C & I & O & N & A & L & E & S
\end{tabular}

\title{
Los retos de la educación en Chile
}

\author{
Ministro Sergio Bitar
}

\section{Documento}

Ante todo, agradezco la invitación de la Directora del Instituto de Estudios Internacionales de la Universidad de Chile, con el que me siento vinculado desde sus primeros tiempos.

Mi intención es aprovechar esta oportunidad para tratar el tema de la educación en su relación con el desarrollo económico y con los acuerdos internacionales que tenemos por delante. Para ello, quiero partir señalando que la nueva economía se basa fundamentalmente en el conocimiento y, en consecuencia, el motor del desarrollo del siglo XXI está cada vez más relacionado con las capacidades y destrezas de la población. En consecuencia, las relaciones internacionales no estarán marcadas por los recursos naturales de que se disponga ni por el dinero que se pueda tener, sino por las capacidades del capital humano.

A mi juicio, los factores que influyen en el éxito en materia de desarrollo económico son, ante todo, un buen manejo macroeco-

* Clase magistral dictada por el Ministro Sergio Bitar, con motivo de la inauguración del año académico del curso de Magíster en Relaciones Internacionales, del Instituto de Estudios Internacionales de la Universidad de Chile, el 24 de abril de 2003. 
Los retos de la educación en Chile nómico, una estructura democrática institucional sólida y transparente, que cuente con mecanismos de justicia previsibles y una adecuada formación tecnológica. Chile es reconocidamente exitoso en cuanto al primero de estos factores. Por lo que toca al segundo, presenta algunas deficiencias que es preciso ir corrigiendo, pero vamos por buen camino con las reformas constitucionales. El tercero, en cambio, marca nuestro rezago a nivel internacional y surge con fuerza el tema del fortalecimiento de la formación del capital humano.

En los estudios sobre el crecimiento, el principal factor explicativo del desarrollo es la calidad de la educación. No tanto la escolaridad sino el conocimiento de las matemáticas y del lenguaje, elementos que en vista de los resultados del SIMCE deben movernos a reflexión. En efecto, pese a que en los últimos diez años hemos avanzado, lo hemos hecho lentamente y ha llegado el momento en que deberíamos pensar en fijarnos un estándar que se asemeje al de los países con los que estamos firmando acuerdos internacionales, como la Unión Europea y los países de Asia. Por el momento, estos últimos han avanzado diez años mientras nosotros avanzamos uno, y esta realidad nos obliga a apurar el paso.

Pero veamos algunas cifras. Entre 1992 y 2002, la población de 5 a 14 años que había completado la escolaridad prebásica aumentó $50 \%$, pero hay que tener presente que la capacidad principal se desarrolla entre las edades de 1 a 6 años y que, en consecuencia, hay que comenzar antes el proceso educativo. En cuanto al porcentaje de chilenos que ha cursado estudios superiores, técnicos o universitarios, pasamos de poco más de un millón en 1992 a dos millones doscientos ochenta mil en 2002. Tenemos en consecuencia un país con más y mejores oportunidades, pero si no aceleramos el ritmo de avance, tardaríamos alrededor de 40 años en alcanzar los niveles de Corea y 50 para llegar a los de Nueva Zelandia.

Ante esta realidad, hay que pensar en las medidas que pueden tomarse. Desde luego, ya se dará un paso simbólico cuando en los próximos días el Congreso Pleno ratifique la aprobación unánime por ambas Cámaras de la reforma constitucional que establece 12 años de escolaridad obligatoria y gratuita hasta los 21 años para todos los chilenos. Recordemos que al aprobarse la Ley de Ins- 
trucción Primaria obligatoria, en 1920, la escolaridad era de cuatro años y la cobertura no pasaba del 50\%; en la actualidad, la cobertura media fluctúa en torno al $90 \%$, pero se calcula que sólo el $14 \%$ de la población adulta es capaz de superar el umbral mínimo requerido para desempeñarse eficazmente en la sociedad de la información. O sea, estamos más de $80 \%$ por debajo del mínimo respecto, por ejemplo, de los Países Bajos, que aparece con un 30\% por debajo del mínimo.

Actualmente, en Chile hay una demanda sostenida de recursos humanos con formación universitaria y, en materia de ingresos, las diferencias de nivel educacional son muy importantes. De acuerdo con estudios recientes, la formación universitaria tiene un retorno de $22 \%$ por cada año adicional, mientras que el de la enseñanza básica es inferior al $4 \%$ y el de la enseñanza media alcanza a un $10 \%$. Esto demuestra que la sociedad premia a las personas que tienen educación universitaria e indica que hay que ampliar las posibilidades de los jóvenes de acceder a este nivel educativo.

En estos años, nuestro compromiso como sociedad ha sido la equidad en el acceso, pero ahora debemos poner el acento en la calidad. Tenemos diferencias muy significativas de calidad entre los distintos establecimientos escolares. Si se mira con atención los resultados académicos de niños y jóvenes, se comprueba que el rendimiento está relacionado estrechamente con el nivel socioeconómico de la familia, en especial con los años de escolaridad de los padres. En cuanto al rendimiento respecto del tipo de establecimiento, en los estratos socioeconómicos bajo y medio bajo, las escuelas municipalizadas tienen mejores resultados que las particulares subvencionadas; en cambio, en el estrato socioeconómico alto, los resultados de los establecimientos privados subvencionados son similares a los de los colegios pagados.

En cuanto al sector educacional como mecanismo de corrección de las desigualdades, un camino, por cierto, es la expansión de la educación superior, que en nuestro país ha sido muy fuerte. La universidad, que hace veinte años formaba a las elites, se ha vuelto una institución que recibe a cohortes cada vez más heterogéneas. El ingreso masivo a las instituciones universitarias ha sido posible tanto por la ampliación de la cobertura y la retención en la educación media como por la multiplicación de la oferta acadé- 
Los retos de la educación en Chile mica, que de las 8 universidades tradicionales existentes en los años ochenta ha aumentado a las 60 que existen actualmente. Sin embargo, esta enorme expansión tiene una consecuencia preocupante para la calidad de los estudios que proporciona esta proliferación de establecimientos, que será preciso abordar con medidas que garanticen que la formación de formadores sea adecuada. Desde luego, deberá establecerse una instancia superior de acreditación de la calidad de los estudios, tema que es objeto del proyecto de ley sobre un Sistema Nacional de Aseguramiento de la Calidad de los Estudios Superiores, que consagra la acreditación institucional y de carreras de pre y posgrado con estándares de calidad y evaluación de pares externos. Este proyecto seguramente será objeto de un prolongado debate, ya que algunos sostienen que acreditar equivale a controlar y que la libertad garantiza la expansión de la educación.

La deserción en la educación superior es especialmente significativa (en los dos primeros años llega a 30\%), pero no es un problema exclusivamente nuestro. $\mathrm{Al}$ respecto, la rigidez y la excesiva extensión de los currículos hacen difícil, si no imposible, que los jóvenes puedan moverse al interior de su institución y este es uno de los motivos de la deserción. Hace poco se realizó en la Universidad Católica de Valparaíso un encuentro al que asistieron unos 16 expertos europeos para debatir el denominado Programa Polonia. Este programa, que establece la forma de conexión de las universidades europeas, contempla la flexibilización del currículo, con carreras más cortas que pueden irse componiendo a lo largo de la vida, de tal modo que se puede partir con una carrera y terminar con una diferente. Es una idea interesante, que hay que estudiar detenidamente.

Además del cambio en la estructura curricular hay que considerar el ingreso por mérito, de tal modo que al que no tenga los medios económicos el Estado le garantice el ingreso a la universidad. Hemos enviado al Congreso un proyecto de ley que establece un nuevo sistema de financiamiento de estudios superiores con aval del Estado para los alumnos de universidades, institutos profesionales y centros de formación técnica autónomos y acreditados.

En Chile aún falta mucho por hacer en la primera etapa de formación del capital humano y lo mismo puede decirse de la situación en el nivel avanzado. Si se considera que en 1997 for- 
mamos un doctor por cada millón de habitantes, mientras que en Argentina la proporción fue de 11, en Brasil de 18, en Finlandia 180, en Corea 106 y en España 150 por millón, vemos que estamos bastante rezagados y que debemos ponernos una meta mucho más ambiciosa para mejorar nuestro posicionamiento internacional.

En materia de ciencia y tecnología, Chile es uno de los países del mundo en que la empresa privada contribuye menos al desarrollo tecnológico. Las cifras son elocuentes: mientras que en nuestro país las empresas aportan menos de $20 \%$ al gasto total en investigación y desarrollo, en otros, incluso economías emergentes, la proporción es muy superior. O sea, a nivel internacional, estamos débiles en el campo de la participación de la empresa y en la relación entre ciencia y educación. Una buena noticia es que estamos por firmar un proyecto importante en ciencia y tecnología con el Banco Mundial, pero debemos considerar medidas tales como incorporar las patentes y la propiedad intelectual como elementos para calcular el aporte fiscal directo a las universidades y fomentar la participación de investigadores chilenos en programas internacionales de investigación científico-tecnológica, como el programa marco con la Unión Europea.

Quiero aprovechar esta oportunidad para referirme brevemente al papel visionario de Claudio Véliz, cuando encauzó las actividades del Instituto de Estudios Internacionales hacia el estudio de la Cuenca del Pacífico, tema que continúa recibiendo atención preferente en esta casa de estudios y que viene muy al caso, puesto que en 2004 seremos anfitriones de la reunión del APEC. En los próximos 20 o 30 años, el crecimiento mundial se va a concentrar mucho en el área del Pacífico, desde China a la costa de los Estados Unidos, que serán dos polos de formación de científicos y técnicos. Por esta razón, Chile debería preocuparse de que haya más profesionales dedicados al área, que observen lo que ocurre, estudien los negocios nuevos que pueden hacerse, y aprendan los idiomas pertinentes.

Respecto de esto último, quiero referirme especialmente a la importancia que reviste actualmente el conocimiento del inglés. En el siglo XXI es muy difícil moverse si no se manejan dos cosas, el inglés y la Internet. Podría decirse que el inglés ha dejado de ser un idioma y se ha convertido en un código básico para la 
comunicación: si uno no lo conoce, no puede hablar, vender ni hacer turismo. Por eso es que hemos iniciado una campaña para la enseñanza del inglés, a todo nivel y no sólo en la educación superior. Hay que concebir formas modernas que permitan aprender este idioma como segunda lengua en forma más rápida, porque ha pasado a ser un instrumento para dar trabajo.

Otro punto que querría señalar es que, como Ministro de Educación, me gustaría poder llegar a acuerdos con Perú y Bolivia para reunir historiadores de ambos países de modo de poder mirar el pasado con proyección al futuro. Si seguimos enseñando la historia como lo hemos hecho hasta ahora, será difícil que nos encontremos y persistirán las odiosidades, mientras que otros países que han tenido guerras mucho más cercanas han podido llegar a establecer una relación mucho más fraterna y superar los conflictos entre ellos.

Finalmente, quiero destacar que en un mundo que mira al futuro, Chile no compite con cobre ni con vino, sino con la calidad de su gente. Por lo tanto, el eje fundamental de su futuro está en la educación y el debate sobre la educación debe situarse en la agenda pro crecimiento con vistas al bicentenario, en el APEC, en los tratados con la Unión Europea y con Estados Unidos. Esto supone más capital humano y este significa más igualdad de oportunidades, más equidad para aprovechar ampliamente los talentos nacionales. Es una forma nueva y necesaria de mirar la política internacional para encarar el futuro de Chile. 